\title{
Use of non-traditional types of plant raw materials for food production within the framework of food security
}

\author{
Ekaterina Pastushkova*, Ekaterina Kryukova, Alexsandr Arisov, Vladislav Tiunov, and \\ Larisa Kokoreva \\ Ural State Economic University, 8 Marta, 62, 620144 Yekaterinburg, Russia
}

\begin{abstract}
Improving food security and quality of life is directly related to providing the population with high-quality products, including functional ones, that help to restore and maintain their nutritional status. The use of plant raw materials as a prescription component in the production of confectionery remains a poorly studied and relevant topic. The use of nontraditional types of plant grain raw materials, including amaranth seeds, in the confectionery industry is due to the high nutritional value and unique chemical composition [1]. This article discusses the possibility of using amaranth seed flour and coconut milk in the recipe of flour confectionery products. Optimal amounts of incorporation of amaranth seed flour and coconut milk in the cookie recipe have been developed. The cookie was evaluated by commodity research, regulated indicators were established, and its biological value was determined.
\end{abstract}

\section{Introduction}

Food security is understood not only as the provision of population with high-quality and safe food products that contribute to maintaining a healthy and active lifestyle, but also as its economic accessibility.

The global concept of food security, adopted at the World Food Summit (1996), is based on the following principles: guaranteed economic availability of food products; optimal supply of nutrients that meets the needs of the human body; providing the population with a sufficient range of food products that allows them to keep a healthy lifestyle and nutrition for all.

The implementation of the principles of food security consists in providing high-quality and safe raw materials components due to the sustainability of the country's food system, which includes product life cycles.

The experience of the Russian Federation in the field of development and improvement of food security consists in solving the following tasks: improving the quality of life of the population and developing the food industry. The most promising direction determining the provision of high-quality and balanced food products to the population is the development

* Corresponding author: pas-ekaterina@yandex.ru 
of specialized products. This direction is characterized by the creation and production of a new generation of food products with specified consumer properties that ensure food security, preferences and quality of life of the population as a whole.

Based on international experience and in accordance with the adopted Program of the Government of the Russian Federation "Healthy nutrition - health of the nation" and "Strategy for improving the quality of food products in the Russian Federation until 2030", the development of scientific approaches to the formation of food quality using plant raw materials is a relevant scientific direction [2].

Confectionery products are in high demand in Russia and are a high-calorie product with a low content of vitamins. The use of non-traditional raw materials containing useful substances - vitamins, micro- and macronutrients, dietary fiber, in the confectionery industry is relevant. [3].

The objective of this study is to develop recipes and evaluate the quality of cookies using non-traditional types of plant raw materials, namely amaranth seed flour and coconut milk.

One of the most effective ways to increase the competitiveness of food enterprises is to produce a range of specialized products enriched with food substances to a level that corresponds to the physiological needs of the body.

The greatest interest has recently been gained by amaranth seeds flour, the raw material for which production is the plant "Amaránthus" - the oldest grain crop, which is the main source of protein up to $35 \%$ (including essential amino acids), easily digestible by the human body [4-7]. Figure 1 shows the chemical composition and nutritional value of amaranth seed flour, \%

The protein content in amaranth seed flour is $12.4 \%$, which helps to regulate cell metabolism, produce hormones, enzymes, increase the immune system, and ensure important functions of the human body. Plant protein of amaranth seeds contains $30 \%$ of amino acids essential for the human body.

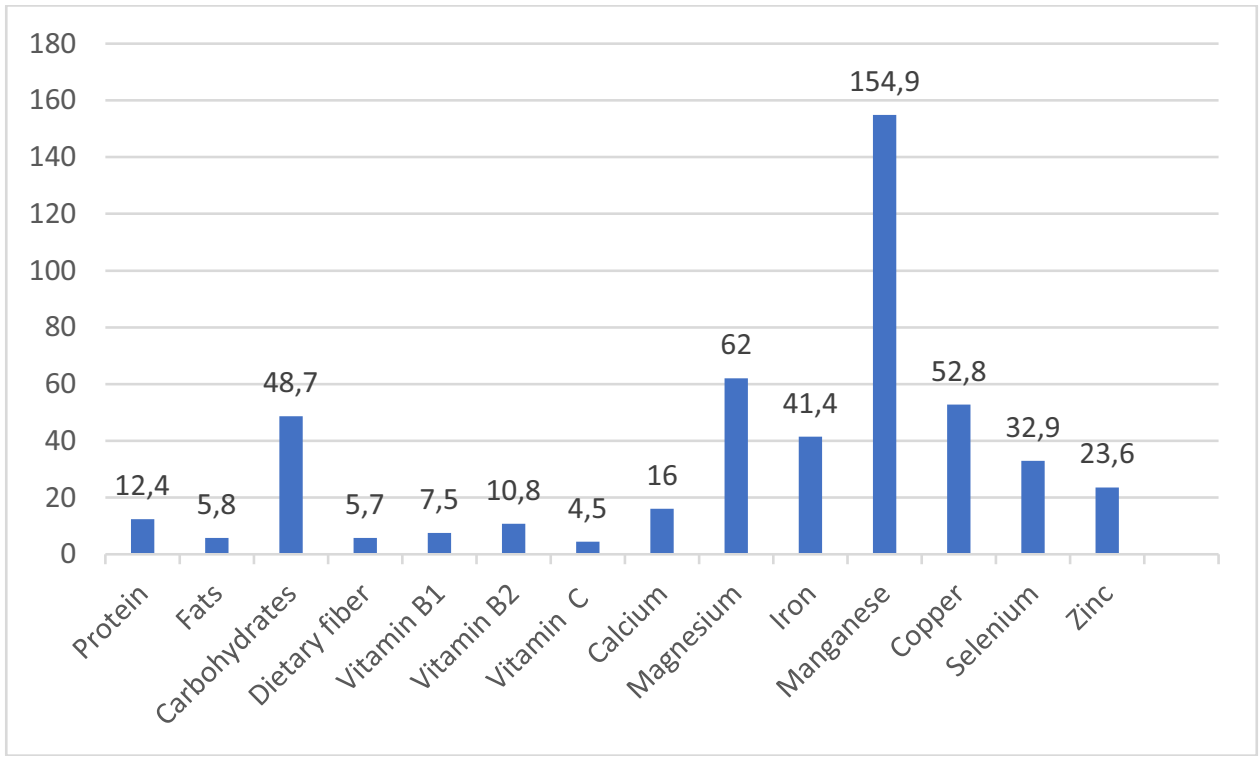

Fig. 1. Chemical composition and nutritional value of amaranth seed flour, \%

Coconut milk is an exotic product obtained from mature coconuts (10-13 months) with the addition of coconut water, containing at least $10 \%$ fat, including polyunsaturated fatty acids, vitamins and trace elements [8]. 


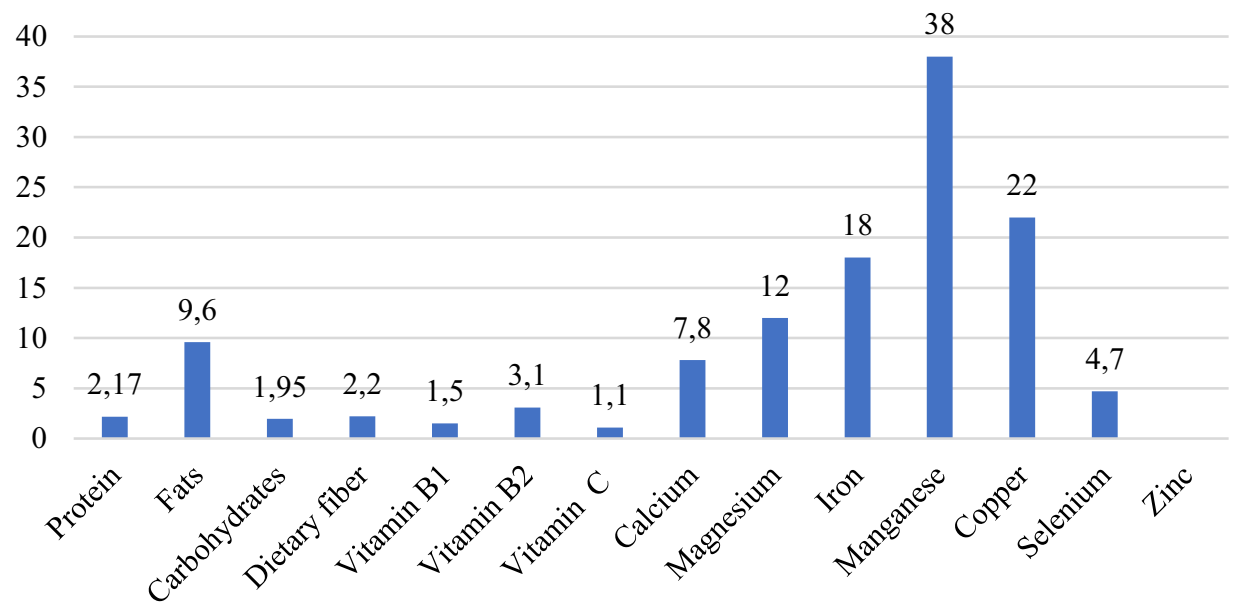

Fig. 2. Chemical composition and nutritional value of coconut milk, \%

The inclusion of coconut milk in the diet allows to meet the daily intake of protein, fat and carbohydrates by $3 \%, 19 \%$ and $1 \%$, respectively, necessary for the body. Also, $100 \mathrm{~g}$ of coconut milk contains $5 \%$ of the daily value of vitamin C, $9 \%$ of the daily value of iron and magnesium, and $8 \%$ of the daily value of potassium [9].

\section{Materials and Methods}

The objects of research are experimental and production samples of butter cookies:

- sample 1 - control sample of butter cookies produced according to the traditional recipe

- sample 2 - test sample with 30\% incorporation of wheat flour and $61 \%$ incorporation of butter into coconut oil

- sample 3 - test sample with $25 \%$ incorporation of wheat flour and $61 \%$ incorporation of butter into coconut oil

- sample 4 - test sample with $20 \%$ incorporation of wheat flour and $61 \%$ incorporation of butter into coconut oil

- sample 5 - test sample with $15 \%$ incorporation of wheat flour and $61 \%$ incorporation of butter into coconut oil

The development of a recipe for butter cookies with partial replacement of wheat flour with amaranth seeds flour and coconut milk is based on the use of mathematical modeling of their composition [10].

In order to achieve this goal, we used generally accepted, standard and original test methods, including organoleptic, physical and chemical methods. The studies were carried out in three-fold repetition, the results of which were processed using statistical programs.

The quality of butter cookies was determined by the following indicators:

- sensory characteristics of the finished product were determined by [11];

- weight fraction of dry substances was determined using the accelerated drying method according to GOST 5900-2014, which consists in drying the product to a permanently dry mass at a certain temperature, and determining the weight loss in relation to the initial weight; 
- sugar weight fraction was determined by the photocolorimetric method according to GOST 5903-89, based on colorimetry of excess of ferricyanide solution after reaction with reducing substances [12];

- fat weight fraction was determined by the extraction method according to GOST 31902-2012, based on the fat extraction from the analyzed sample of the product with a solvent, followed by its removal;

- alkalinity (according to GOST 5898-87). The essence of the method is to neutralize the alkaline substances in the product using sulfuric acid and in the presence of an indicator, until the yellow staining of the solution appears;

- wetability (according to GOST 10114-80), consists in determining the amount of water absorbed by the product when it is immersed for 2 minutes.

- amino acid composition was determined by high-performance liquid chromatography (HPLC) method with pre-column derivatization by OPA and FMOC agents in food products (Agilent 1260 Infinity II). The method is based on the passage of the analyzed substance through the sorbent layer with a flow of eluent (liquid or gas), in which it is divided into its components. Depending on the composition, the components move at different speeds - those that are better fixed on the sorbent are slower[13];

- food and energy value of the product was determined by the calculation method [14].

\section{Results and Discussion}

At the initial stage of the experiment, mathematical modeling was used to develop the recipe [11]. Figure 3 shows models of recipes for butter cookies with different contents of amaranth seed flour and coconut milk.

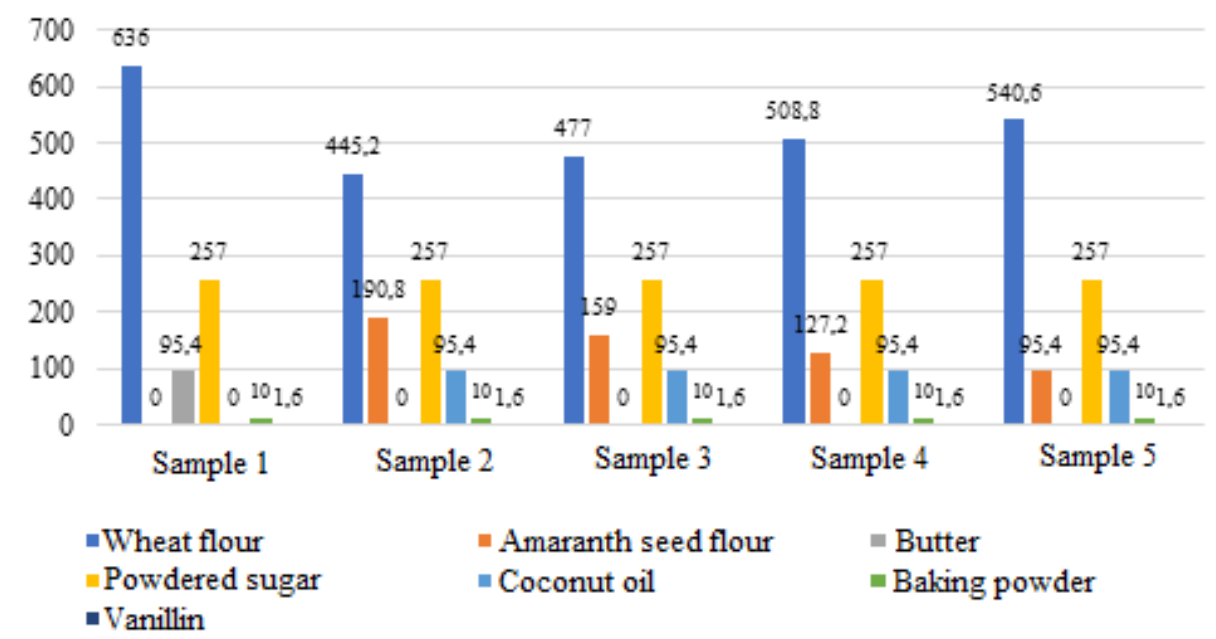

Fig. 3. Recipe composition of experimental samples of butter cookies, $\%$

Identification of the optimal recipe composition for the incorporation of wheat flour into amaranth seed flour is based on a comparative analysis of the organoleptic parameters of the control sample with the experimental ones. Characteristics of organoleptic parameters of butter cookies experimental samples are presented graphically in Fig. 4. 


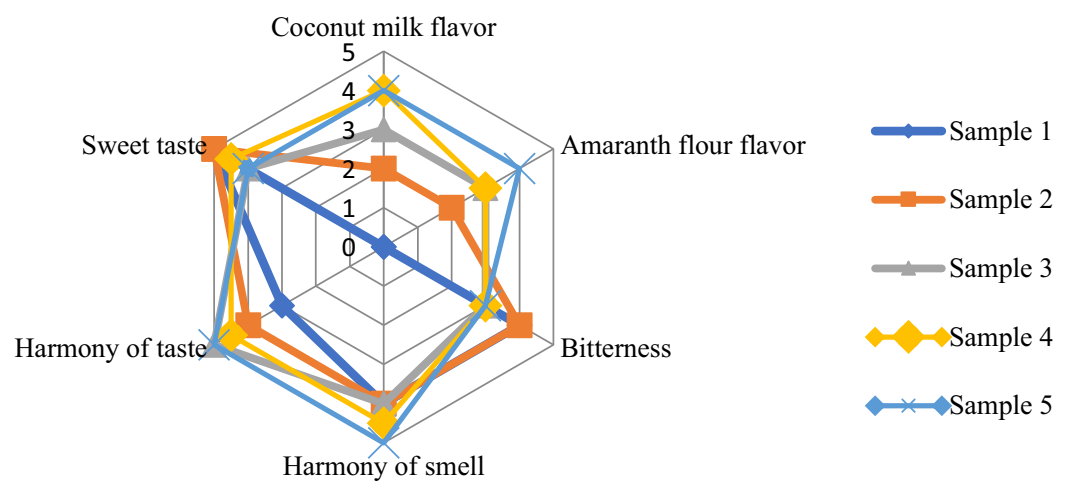

Fig. 4. Profilogram of comparative analysis of sensory characteristics of control and experimental samples of butter cookies, score

Based on the conducted tasting assessment of sensory characteristics, it was found that the most acceptable taste and aroma portrait has a sample of butter cookie No. 5 with an incorporation of wheat flour of $15 \%$, the color is light brown, uniform over the entire surface, the taste is sweet with a taste of amaranth and coconut, the aftertaste is pronounced, long.

Further studies of physical and chemical parameters were carried out in the sample of butter cookies No. 5 (table 1).

Table 1 - Physical and chemical parameters of the test sample $(n=3)$

\begin{tabular}{|l|c|c|}
\hline \multicolumn{1}{|c|}{ Indicator } & $\begin{array}{c}\text { Requirements in accordance } \\
\text { with } \\
\text { GOST 24901-2014 }\end{array}$ & $\begin{array}{c}\text { Actual results of } \\
\text { the study }\end{array}$ \\
\hline Moisture weight fraction, \% & Max 16.0 & $12.8 \pm 0.03$ \\
\hline $\begin{array}{l}\text { Weight fraction of total sugar in } \\
\text { terms of dry matter, \% }\end{array}$ & Max 45.0 & $39.1 \pm 0.04$ \\
\hline $\begin{array}{l}\text { Weight fraction of fat in terms of } \\
\text { dry matter, \% }\end{array}$ & Max 30.0 & $25.3 \pm 0.15$ \\
\hline Alkalinity, deg & Max 2.0 & $1.2 \pm 0.03$ \\
\hline Water absorption, $\%$ & Min 150.0 & $131.8 \pm 1.21$ \\
\hline
\end{tabular}

The obtained results of physical and chemical parameters of the experimental sample No. 5 of butter cookies meet the regulated requirements of the standard, and, therefore, allows to make a conclusion about the correct selection of recipe components and quantitative incorporation of wheat flour into amaranth seed flour and butterl into coconut milk.

At the next stage, the nutritional value of butter cookies is determined (table 2).

Table 2 - Nutritional value of the test sample

\begin{tabular}{|c|c|c|}
\hline Indicators & $\begin{array}{c}\text { Content in } 100 \mathrm{~g} \text { of the } \\
\text { product }\end{array}$ & In \% of the daily norm \\
\hline Proteins & $18.7 \mathrm{~g}$ & 25.9 \\
\hline Fats & $51.6 \mathrm{~g}$ & 63.7 \\
\hline Carbohydrates & $167.71 \mathrm{~g}$ & 39.8 \\
\hline Energy value & $501 \mathrm{kcal}$ & 17.9 \\
\hline
\end{tabular}


The data presented in table 2 indicate that this test sample of butter cookies meets the daily intake of protein, fat and carbohydrates by $25.9 \%, 63.7 \%$ and $39.8 \%$, respectively.

At the next stage, a comparative analysis of the biological value of the control and experimental sample of butter cookies No. 5 was carried out (Fig. 5)

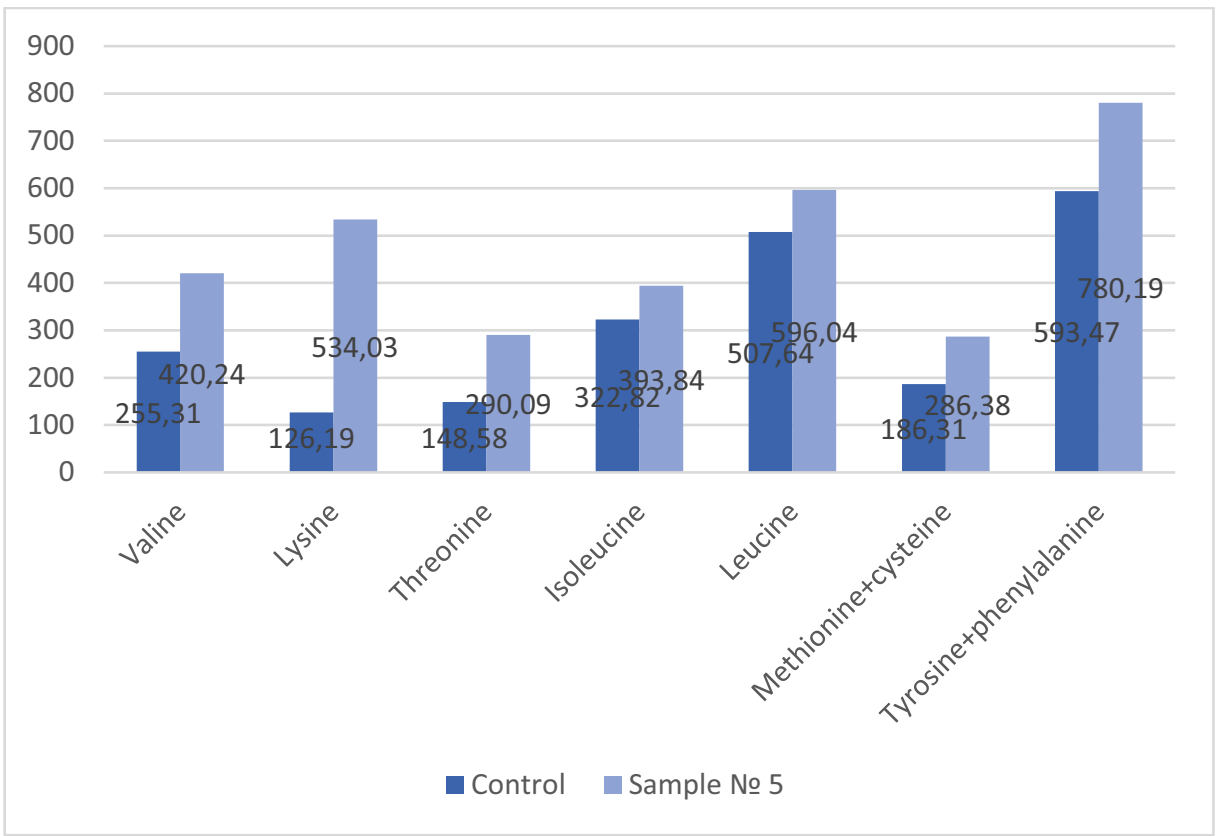

Fig. 5. Amino acid composition of the butter cookies test sample No. $5, \mathrm{mg} / 100 \mathrm{~g}$

Based on the data presented in figure 5, it was found that in the test sample of butter cookies No. 5, the content of valine exceeds 1.6 times that in the control sample, lysine 4.2 times, threonine -1.9 times. According to the total content of amino acids, there is an excess in 1.6 times in the test sample than in the control sample, which causes an increase in metabolism in the body, an increase in muscle tone, and increases the body's resistance.

\section{Conclusion}

In order to develop the healthy food industry and increase the demand for products with a balanced composition, new flour confectionery products have been developed, namely butter cookies with partial or full incorporation of amaranth flour and coconut milk. Using the method of mathematical modeling, the quantitative content of amaranth flour and coconut milk in the recipes of butter cookies was selected, taking into account the functional orientation, increase of consumer properties, food and biological values.

According to the results of commodity research assessment of the quality of butter cookies with partial incorporation of wheat flour into amaranth seed flour, it was found that the increase in sensory characteristics, while physical and chemical (including moisture content $-12.8 \%$; w.f. of total sugar content in terms of dry matter $-39.1 \%$; fat mass fraction in terms of dry matter $-25.3 \%$, alkalinity -1.2 deg, wetability $-131.8 \%$ ) meet the requirements of regulatory documentation. It has been experimentally proved that the content of essential amino acids has increased in a test sample of butter cookies, and, consequently, it contributes to an increase in metabolism in the body, an increase in the tone of muscle tissue, body resistance. 
It was experimentally established that in the experimental sample of butter cookies No. 5 , essential amino acids on average meet up to $35 \%$ of the daily needs of lysine, valine and threonine, considering the recommended level of their consumption.

Thus, based on the results of the study of butter cookies No. 5 with partial incorporation of amaranth seeds flour and coconut milk, enhancing nutrition value, nutrient composition, and, consequently, the prevention of non-communicable diseases such as hypertension, high cholesterol, coronary heart disease can be attributed to products with functional orientation and allowing to keep a healthy lifestyle.

\section{References}

1. W. Davis, Rodale Books, 15 (2011)

2. D. Ogrodowska, R. Zadernowski, S. Czaplicki, D. Derewiaka, B. Wronowska, Polish Journal of Food and Nutrition Sciences, 165 (2014)

3. O. Chugunova, N. Leyberova, E. Kryukova, Confectionery production, 1, 20 (2016)

4. A. Chemenkova, S. Leonova, T. Nikiforova, A. Zagranichnaya, E. Chernenkov, O. Kalugina, E. Badamshina, I. Gazeev. OnLine Journal of Biological Sciences, 19 (2019)

5. M. Venturi, V. Galli, N. Pini, S. Guerrini, L. Granchi, Foods, 8, 218 (2019)

6. A.M. Calderón De La Barca, M.E. Rojas-Martínez, Plant Foods for Human Nutrition, 3, 65 (2010)

7. K. Karandeep, C. Navnidhi, S. Poorva, Foods and Raw Materials, 2, 419 (2019)

8. S. Gebreil, M. Ali, E. Mousa, Food and Nutrition Sciences, 336 (2020)

9. A. Rustemova, N. Kydyraliev, M. Sadigova, N. Batyrbayeva, BIO Web of Conferences, 17 (2019)

10. V.G. Lobanov, Y.I. Slepokurova, I.M. Zharkova, T.N. Koleva, Y.F. Roslyakov, A.P. Krasteva, Foods and Raw Materials, 474 (2018)

11. E. Pastushkova, O. Chugunova, N. Leyberova, Modern problems of science and education, 1-1, 110 (2015)

12. GOST 31986-2012. Public catering service. Method of sensory evaluation of catering products, 12 (2014)

13. GOST R 54607.2-2012. Public catering services. Methods of laboratory control of public catering H. J. Van Niekerk, M. J. Viljoen, Land Degradation \& Dev., 16 (2005)

14. Guidelines for laboratory quality control of public catering products, 131 (1997) 